[FUKUSHIMA RADIATION SYMPOSIUM 2013]

\title{
PREGNANT AND BIRTH SURVEY AFTER THE GREAT EAST JAPAN EARTHQUAKE AND FUKUSHIMA DAIICHI NUCLEAR POWER PLANT ACCIDENT IN FUKUSHIMA PREFECTURE
}

\author{
KEIYA FUJIMORI ${ }^{1)}$, YASUHISA NOMURA ${ }^{1)}$, KENICHI HATA ${ }^{2)}$ \\ ${ }^{1)}$ Department of Obstetrics and Gynecology, School of Medicine, Fukushima Medical University, ${ }^{2)}$ Fuku- \\ shima Association of Obstetricians and Gynecologists
}

(Received November 28, 2013, accepted December 29, 2013)

Residents in Fukushima are still suffering from the catastrophe caused by the Great East Japan Earthquake, which was followed by a powerful tsunami and the Fukushima Daiichi Nuclear Power Plant accident. Furthermore, another type of damage was the created by the nuclear accident in the form of 'fuhyohigai', which is defined as economical, psychological and political damage attributed to baseless rumors or confused public anxiety under extreme disasters of this scale. It is for this reason that in the opinions of some, much more time is required for Fukushima to make a full recovery.

From a medical point of view, the biggest concern at this point is people's ambiguous but indelible anxiety regarding continuous radiation exposure, regardless of the dose levels being significantly low. In the field of obstetrics, a decrease in delivery rate of about $20 \%$ has been reported in Fukushima prefecture as a whole. However, the situation differs from region to region, depending on the extent of radioactive contamination. For example, in the Aizu region where the ambient radiation levels are significantly low, the delivery didn't decrease even after the accident, while that in the Nakadori region, a relatively highly contaminated region, decreased to a worrying level. On the other hand, a general health survey in Fukushima revealed that the incidence of congenital malformation in single pregnancy was $2.73 \%$ in 2011 and $2.32 \%$ in 2012 . These two values can be judged as normal, because the average rate observed in Japan is 3 to $4 \%$.

Currently, four lines of investigation or support are underway for pregnant and nursing women in Fukushima. The first is a general health survey,

\section{Miscarriage rate (per100 pregnancies)}

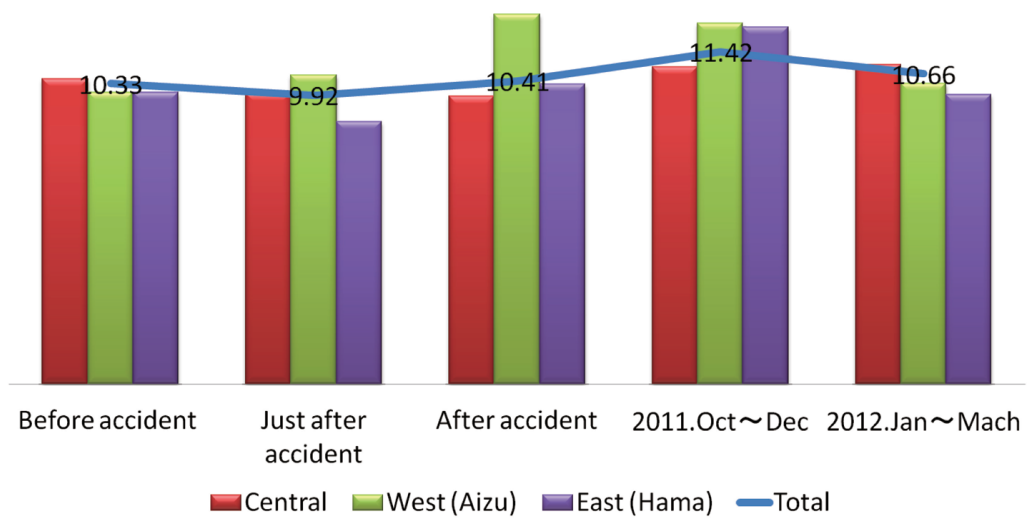

Before accident :

Jan 2011-March 11,2011

Just after accident : $\quad$ March 12, 2011-Jun 2011

After accident : July 2011-Sept 2011

Corresponding author : Keiya Fujimori E-mail : fujimori@fmu.ac.jp

https://www.jstage.jst.go.jp/browse/fms http://www.fmu.ac.jp/home/lib/F-igaku/ 


\section{Induced abortion rate (per100 pregnancies)}

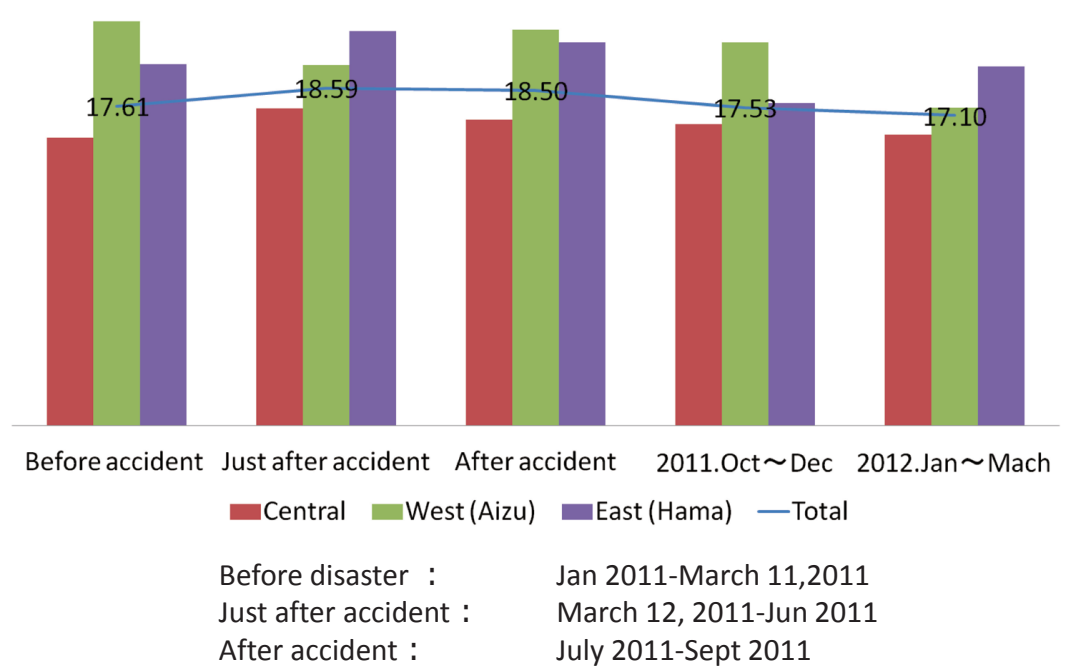

which is conducted by the prefectual government of Fukushima. Secondly, the Japan Environment and Children's Study (JECS), a national birth cohort study on children's health and the environment, was launched by the Ministry of the Environment of Japan and has been extended to the whole Fukushima since October 2012. The third is the survey for the incidence of congenital malformations, organized by the Fukushima Association of Obstetricians and Gynecologists. Finally, our department is responsible for investigating the incidence of pregnancy, miscarriage and induced abortion.

Our analysis revealed that the miscarriage rate has remained at 10 to $11.5 \%$ after the disaster (10 to $15 \%$ on general average).

Furthermore, the incidence of induced abortion was 17 to 18.5 cases/100 cases after the disaster, which also indicated no change when compared with that before the accident.

Regarding the low ambient radiation level, it is in our opinion that the provision of previous scientific data alone is insufficient enough to lessen or remove the anxiety being experienced by local residents over the health of themselves and that of generations to come. Operating under the condition where more scientific evidence is required in Fukushima, it is our duty to provide continuously the residents with a sense of both safety and security, to enable them to return to the ordinary life they had prior to the accident. 